\title{
Investigation of the Criteria for Fluid Selection in Rankine Cycles for Waste Heat Recovery"
}

\author{
M. Aslam Siddiqi, and Burak Atakan ** \\ Thermodynamics, IVG, Department of Engineering, \\ University of Duisburg-Essen, Lotharstr. 1, D-47057 Duisburg, Germany \\ E-mail:aslam.siddiqi@uni-due.de,burak.atakan@uni-due.de
}

\begin{abstract}
The organic Rankine cycle is a promising way for the conversion of low temperature heat to electricity. Different fluids can be used in Rankine cycles for the utilization of waste heat. The suitability of a certain fluid will depend on its thermodynamic properties as well as on the conditions at which the heat is available, thus it is often unclear if an organic fluid has any advantage compared to inorganic fluids like water. Various substances starting from the refrigerants to high boiling organic liquids have been investigated as possible working fluids for the different temperature ranges at which the waste heat is available. The present communication reports the results for three different classes of substances: 1) a hydrocarbon (n-heptane); 2) two refrigerants 1.1.1.3.3-pentafluoropropane (R245fa) and pentafluoro butane mixture (Solkatherm, SES36); and, 3) water in the intermediate temperature range (473 to $773 \mathrm{~K}$ ) where the exhaust gases of combustion engines may be used as energy source for cogeneration. In this range it turns out that for many conditions, water and heptane are well suited working fluids for cogeneration systems. In the present investigation, the attention was not laid on the cycle efficiency alone, but also on the total exergy usage from an enthalpy stream (e.g. exhausts gas). This is taken into account while discussing the quality of the process. The results for different thermodynamic parameters and the surface area of the heat exchanger have been discussed. $T-\dot{H}$ diagrams were also used for judging the suitability of a fluid. It turns out that water is well suited for many cases in the intermediate temperature regime.
\end{abstract}

Keywords: ORC; Rankine cycle; Thermal efficiency; T-H diagram; Exergy loss, CHP.

\section{Introduction}

In the last years, the utilization of low grade heat sources, such as exhaust gases of gas turbines, engines, geothermal resources, the waste heat from industrial plants, and the energy recovery from molten carbonate fuel cells is becoming more and more important (Drescher \& Brüggemann, 2007; Hung, 2001; Hung, Shai, \& Wang, 1997; Yamamoto, Furuhata, Arai \& Mori, 2001; Angelino \& Colonna di Paliano, 2000a, 2000b). Energy recovered from waste heat streams could supply a substantial part or all of the electric power required by a plant, at no additional cost (Mago \& Chamra, 2008). Therefore, heat recovery offers a great opportunity to conserve by productively using the waste energy to reduce overall plant energy consumption and simultaneously decrease $\mathrm{CO}_{2}$ emissions.

The organic Rankine cycle is a promising way for the conversion of low and medium temperature heat to electricity (Drescher \& Brüggemann, 2007; Hung, 2001; Hung, Shai, \& Wang, 1997; Yamamoto, Furuhata, Arai \& Mori, 2001). There are a number of fluids which can be used as the working medium. So the question is which fluid is most suitable under the specified conditions. The suitability of the fluid will depend on its thermodynamic properties as well as on the conditions at which the heat is available (Saleh, Koglbauer, Wendland \& Fischer, 2007). We are working on a long term program to investigate various substances starting from the refrigerants to high boiling organic liquids to suggest suitable working fluids for the different temperature ranges at which the waste heat is available:

a) $373 \mathrm{~K}$ to $473 \mathrm{~K}$, e.g. geothermal resources

b) $473 \mathrm{~K}$ to $773 \mathrm{~K}$, e.g. waste heat from industries, exhaust from engines

c) above $773 \mathrm{~K}$, e.g. biomass combustion.

A large amount of waste heat energy is released into the environment from exhaust gases from turbines and engines as well as from industrial plants. The geothermal resources and solar energy also offer themselves as low grade heat sources.

The present study assumes a constant exhaust gas stream at $773 \mathrm{~K}$ as the exergy source which transfers heat to the cycle, which is a reasonable temperature for (Diesel generator) engine exhausts. In contrast to most previous publications the combined generation of heat and power (CHP) using organic Rankine cycles is studied in the present work, meaning that the heat rejection of the cycle shall be used for heating purposes. Such systems can e.g. be used as the energy supply for hospitals. Thus, to be useful for this purpose, a heating of the cooling water to $85^{\circ} \mathrm{C}$ was studied.

The organic Rankine cycle (ORC) offers a means to recover at least a part of low grade heat. The recovery of low grade waste heat is not only economical but also helps to reduce the atmospheric pollution (emission of $\mathrm{CO}_{2}, \mathrm{NO}_{\mathrm{x}}$, $\mathrm{CO}$ and other pollutants). It can be applied to small systems too. Some recent studies on the use of organic Rankine

*This paper is an updated version of the paper published in the ECOS'10 proceedings. It is printed here with the permission of the authors and organizers.

${ }^{* *}$ Corresponding Author 
cycles for low grade heat recovery from various sources can be found in (Drescher \& Brüggemann, 2007; Hung, 2001; Hung, Shai, \& Wang, 1997; Yamamoto, Furuhata, Arai \& Mori, 2001; Saleh, Koglbauer, Wendland \& Fischer, 2007). However, the best choice of the fluid and the parameters for a given heat recovery problem remains unresolved. Hydrocarbons such as pentane to dodecane, aromatics, siloxanes and numerous refrigerants have been investigated (Drescher \& Brüggemann, 2007; Angelino \& Colonna di Paliano, 2000a, Saleh, Koglbauer, Wendland \& Fischer, 2007) in part also in comparison to water (Hung, Shai, \& Wang, 1997; Yamamoto, Furuhata, Arai \& Mori, 2001). It was pointed out that all these fluids can be used efficiently. However, no fluid could be recommended which is thermodynamically suitable as well as environmentally safe (Angelino \& Colonna di Paliano, 2000a). For ORC with maximum temperatures of $250{ }^{\circ} \mathrm{C}$ and $300{ }^{\circ} \mathrm{C}$ and pressures up to $5 \mathrm{MPa}$ (Lai, Wendland \& Fischer, 2011) found cyclopentane to be the best fluid under the conditions studied. In this paper the results for representative substances viz., heptane, two refrigerants (R245fa, $\mathrm{CF}_{3} \mathrm{CH}_{2} \mathrm{CF}_{2} \mathrm{H}$ and SES36, which is an azeotropic mixture of $\mathrm{CF}_{3} \mathrm{CH}_{2} \mathrm{CF}_{2} \mathrm{CH}_{3}$ and a perfluoro-polyether) and water are presented for the case of waste heat availability at $773 \mathrm{~K}$. Refrigerants like the latter two are marketed for special applications, e.g. at low temperatures, but often it is unclear whether they may also be useful in different temperature ranges. Often small companies who made good experiences with a certain fluid in previous applications prefer to stick to this fluid also in different temperature range applications. Such kind of questions motivated us to select these two fluorinated refrigerants for the present investigation.

Apart from the total efficiencies, the size of the heat exchanger area is roughly estimated for each process, since this is an important factor regarding the investment costs. The cycles are studies for different evaporator pressures of up to 16 bar, which is a reasonable value for single stage turbines and also for safety reasons in small devices.

\section{Method}

The working principle of a Rankine cycle is well known and can be found in any standard thermodynamic text book. Using an organic fluid does not change anything in principle. Only the shape of the saturation curve changes depending on the fluid. However, the model used for the calculations and the numbering of the different states is shown in Figure 1 for a ready reference.

The related qualitative T-s diagram is also drawn in Figure 2. An enthalpy stream of hot air, simulating an exhaust gas, at a definite temperature is available from an industrial process or an engine. Energy will be transferred as heat to the working fluid of a Rankine cycle. The Rankine cycle produces electricity and rejects the heat at a lower temperature which can be used further for the heating of cold water (W). The equations used for the model process calculations are summarized below.

The working fluid which leaves the condenser as saturated liquid at a lower pressure (state $5, \mathrm{p}=\mathrm{p}_{\text {cond }}$ ) is brought to a higher pressure $\left(p=p_{\text {boiler, }}\right.$ state 0$)$ with the help of a pump.

The specific work of the pump is then

$w_{50}=\frac{v\left(p_{\text {boiler }}-p_{\text {cond }}\right)}{\eta_{P}}$

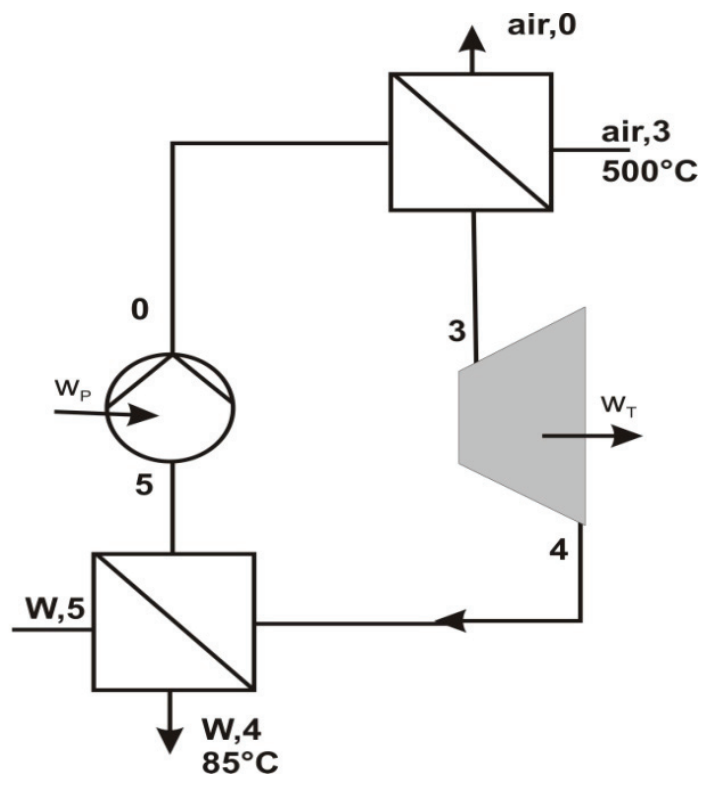

Figure 1. The ORC system used in this study.

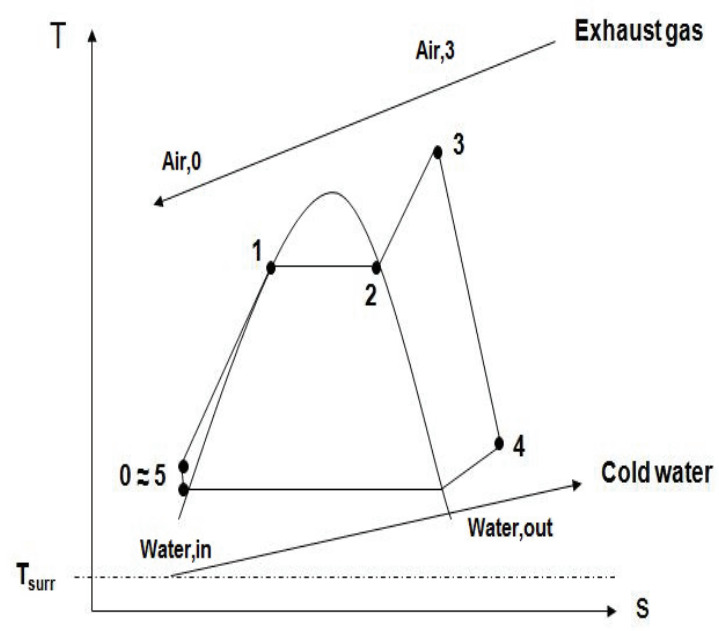

Figure 2. The T-s diagram for the system shown in Figure 1.

where $v$ is the specific volume of the pure saturated liquid at state 5 . Thus

$h_{F, 0}=h_{F, 5}+w_{50}$

The subscript $F$ refers to the fluid of the Rankine cycle and the numbers refer to different states.

The working fluid receives energy from the hot gas stream via a counter current heat exchanger and is vaporized in three stages:

a) Heating of the working fluid up to boiling (state 0 $\rightarrow$ state 1$)$

b) Complete vaporization of the working fluid (state 1 $\rightarrow$ state 2)

c) Superheating of the fluid (state $2 \rightarrow$ state 3 ).

The energy balance across the heat exchanger gives:

$\dot{m}_{F} \cdot\left(h_{F, 3}-h_{F, 0}\right)+\dot{m}_{\text {air }} \cdot\left(h_{\text {air }, 0}-h_{\text {air }, 3}\right)=0$

The heat exchanger may be thought to be made up of three parts and in each part one of the above operations takes place. So the first part, i.e. the heat transfer needed 
for raising the temperature of the working fluid to the boiling temperature, can be written as:

$$
\dot{Q}_{\text {add }, 01}=k_{01} \cdot A_{01} \cdot \Delta T_{L M T D, 01}=\dot{m}_{F} \cdot\left(h_{F, 1}-h_{F, 0}\right)
$$

The logarithmic mean temperature difference $\Delta \mathrm{T}_{\mathrm{LMTD}}$ is defined as:

$$
\Delta T_{L M T D, 01}=\frac{\Delta T_{0}-\Delta T_{1}}{\ln \left(\frac{\Delta T_{0}}{\Delta T_{1}}\right)}
$$

The pinch point for the heat exchanger (states: 0-3) restricts the maximum mass flow rate in the cycle, while the pinch point in the heat rejection from the cycle limits the maximum cooling water flow rate.

The temperature of air in state 1 is written as

$$
T_{\text {air }, 1}=T_{\text {air }, 0}+\frac{\dot{m}_{F} \cdot\left(h_{F, 1}-h_{F, 0}\right)}{\dot{m}_{\text {air }} \cdot c_{p, a i r}}
$$

Similar equations hold for the second and the third part of the heat transfer.

The superheated vapour is then expanded in a turbine (state $3 \rightarrow$ state 4 ) to the pressure of the condenser, $p_{\text {cond }}$ :

$$
w_{34}=\eta_{\mathrm{T}} \cdot\left(h_{F, 4 s}-h_{F, 3}\right)
$$

The isobaric condensation of the vapour proceeds to the state of saturated liquid (state $4 \rightarrow$ state 5 ). The heat will be transferred from the cycle to the cold water (Index: W) running in the condenser.

$$
\dot{Q}_{\text {rem }}=\dot{m}_{F} \cdot\left(h_{F, 5}-h_{F, 4}\right)=\dot{m}_{W} \cdot\left(h_{W, 4}-h_{W, 5}\right)
$$

Various parameters (e.g. the thermal efficiency of the cycle $\eta_{\text {th,F }}$, the total efficiency $\eta_{\text {th,total }}$, the net power of the process $\mathrm{P}_{\text {net }}$, the exergy loss of the hot stream and the $T-\dot{H}$ diagram for the process) are used to evaluate system performance. The thermal efficiency of a Rankine cycle is defined as

$$
\eta_{t h, O R C}=\frac{\left|w_{50}+w_{34}\right|}{q_{03}}=\frac{\left|w_{50}+w_{34}\right|}{\left(h_{F, 3}-h_{F, 0}\right)}
$$

This efficiency of the cycle does not take into account the residual enthalpy which is lost with the exhaust at a temperature higher than the temperature of the surroundings. The exhaust gas at the exit of the heat exchanger cannot be cooled down to the temperature of the surroundings due to the pinch point restriction and thus contributes to the exergy loss.

A more realistic approach will be to consider this enthalpy loss and define the thermal efficiency of the complete process, viz., $\eta_{\text {th,total }}$

$\eta_{\text {th }, \text { total }}=\frac{\left|\dot{m}_{F} \cdot\left(w_{50}+w_{34}\right)+\dot{m}_{W} \cdot w_{P, W}\right|}{\dot{m}_{\text {air }} \cdot c_{p, \text { air }} \cdot\left(T_{\text {air }, 3}-T_{\text {air }, \text { surr }}\right)}$

In order to make the comparisons easier, the mass flow rate of the air was chosen such that the term in the denominator gives $1000 \mathrm{~kW}$, meaning the maximum possible heat transfer to the cycle would correspond to this value.

The net power delivered by the system is

$$
P_{n e t}=\left|\dot{m}_{F} \cdot\left(w_{50}+w_{34}\right)+\dot{m}_{W} \cdot w_{P, W}\right|
$$

$w_{P, W}=v_{W, 5} \cdot \Delta p_{P, W} / \eta_{P, W}$ be

If the air is cooled up to $\mathrm{T}_{\text {airsurr }}$ the exergy loss rate will

$$
\begin{gathered}
\dot{E}_{\text {Process }}=\dot{m}_{\text {air }} \cdot\left[\left(h_{\text {air }, 3}-h_{\text {air }, \text { surr }}\right)-T_{\text {surr }} \cdot\left(s_{\text {air }, 3}-s_{\text {air }, \text { surr }}\right)\right] \\
-P_{\text {net }}-\dot{m}_{W} \cdot\left[\left(h_{W, 4}-h_{W, \text { surr }}\right)-T_{\text {surr }} \cdot\left(s_{W, 4}-s_{W, \text { surr }}\right)\right]
\end{gathered}
$$

This formula assumes that the air exhausted to the atmosphere will be equilibrated with the surrounding without further usage and that some exergy is finally present in the fluid stream.

In addition to this, the surface area of the heat exchanger required for the complete heat transfer is also very important from the point of view of its cost. This may be estimated using Eqn. (4) for the three parts of the heat exchanger using typical values for the overall heat transfer coefficient $k$.

Description of the model process. All properties were taken from (Lemmon, Huber, \& Mclinden, 2007; Solvay, 2009). The model process was described by the following parameters:

Surroundings: $\mathrm{T}_{\text {surr }}=298.15 \mathrm{~K}, \mathrm{p}_{\text {surr }}=101.3 \mathrm{kPa}$.

Gas Stream: Air, ideal gas $\left[c_{p}=1.004 \mathrm{~kJ} /(\mathrm{kg} \mathrm{K})\right]$ entering at $773 \mathrm{~K}$. The mass flow rate was constant at $2.097 \mathrm{~kg} / \mathrm{s}$ resulting in a maximum possible heat flow rate of $1000 \mathrm{~kW}$. The exit temperature of the gas stream from the heat exchanger was calculated according to a pinch point analysis for the studied maximum temperature and pressure of the cycle fluid, leading to gas exhaust temperature $\mathrm{T}_{\text {surr. }}$.

Heat Exchangers: adiabatic towards the surroundings, isobaric heat transfer. Overall heat transfer coefficients, gas to liquid: $\mathrm{k}_{\mathrm{l}, \mathrm{g}}=40 \mathrm{~W} /\left(\mathrm{m}^{2} \mathrm{~K}\right)$ [also in 2-phase] and gas to gas: $\mathrm{k}_{\mathrm{g}, \mathrm{g}}=20 \mathrm{~W} /\left(\mathrm{m}^{2} \mathrm{~K}\right) \cdot \Delta \mathrm{T}_{\text {pinch }}=10 \mathrm{~K}$ was taken as the temperature difference at the pinch point. Thus, the temperature of the hot exhaust gas at the exit of the heat exchanger is throughout higher than the ambient temperature.

Condenser: The conditions for the cooling water were $\mathrm{T}_{\mathrm{W}, 5}=298.15 \mathrm{~K} ; \mathrm{T}_{\mathrm{W}, 4}=358.15 \mathrm{~K}$; and $\eta_{\mathrm{P}, \mathrm{W}}=0.7$. The cycle pressure in the condenser was chosen such that the saturation temperature of the fluid was $T_{F, s a t}=363.15 \mathrm{~K}$ if not mentioned otherwise.

The isentropic efficiencies of the turbine and pump were both taken as 0.85 .

The boiler pressure was varied between 3 and 16 bar. The turbine entrance temperature $T_{F, 3}$ was varied from the saturation temperature of the investigated fluid up to the maximum temperature calculated according to the pinch point analysis. At higher pressures the design of the turbine gets complex, and due to the flow velocities at the turbine exit more than one stage is needed.

\section{Results and Discussion}

The parameters defined by Eqns. (9)-(11) and (13), and the required surface areas for the heat exchanger were calculated. The needed thermodynamic parameters, viz. the enthalpies in different states were taken from (Lemmon, Huber, \& Mclinden, 2007; Solvay, 2009). Some representative results of the calculations are summarized in Table 1. This table also shows the exergy losses in different process steps which will be analysed in the later part. 
Table 1: Temperature $T_{\text {air, },}$, Temperature $T_{F, 3}$, mass flow rate of the working fluid $\dot{m}_{F}$, the volumetric flow rate at turbine inlet $\dot{V}_{3}$, the volumetric flow rate at turbine outlet $\dot{V}_{4}$, total thermal efficiency $\eta_{\text {th, total }}$, turbine power $P_{\text {Turbine, }}$ pump power $P_{\text {Pump }}$, the net power $P_{\text {net }}$, the required surface area of the heat exchanger $A$, exergy loss rate in boiler $\dot{E}_{\text {Boiler }}$, exergy loss rate in condenser $\dot{E}_{\text {Conderser }}$, exergy loss rate in turbine $\dot{E}_{\text {Turbine }}$, the exergy loss rate in the exhaust $\dot{E}_{\text {Exhaust }}$, and exergy loss rate for the complete process at 16 bar.

\begin{tabular}{lllll}
\hline & Water & Heptane & R245fa & SES36 \\
\hline $\mathrm{T}_{\text {air }, 0}(\mathrm{~K})$ & 433 & 373 & 373 & 373 \\
$\mathrm{~T}_{\mathrm{F}, 3}(\mathrm{~K})$ & 523 & 523 & 523 & 493 \\
$\dot{m}_{F}(\mathrm{~kg} / \mathrm{s})$ & 0.282 & 1.299 & 2.512 & 3.300 \\
$\dot{V}_{3}\left(\mathrm{~m}^{3} / \mathrm{s}\right)$ & 0.0400 & 0.0247 & 0.0475 & 0.0383 \\
$\dot{V}_{4}\left(\mathrm{~m}^{3} / \mathrm{s}\right)$ & $0.0003^{\mathrm{a})}$ & 0.6927 & 0.0812 & 0.1331 \\
$\eta_{\text {th, total }}$ & 0.130 & 0.119 & 0.031 & 0.058 \\
$P_{\text {Turbine }}(\mathrm{kW})$ & 132.2 & 125.4 & 35.1 & 63.8 \\
$P_{\text {Pump }}(\mathrm{kW})$ & 0.5 & 3.7 & 1.7 & 3.6 \\
$P_{\text {net }}(\mathrm{kW})$ & 129.6 & 119.2 & 30.6 & 58.3 \\
$A\left(m^{2}\right)$ & 219.0 & 320.3 & 300.3 & 322.1 \\
$\dot{E}_{\text {Boiler }}(\mathrm{kW})$ & 96.7 & 93.8 & 149.4 & 134.7 \\
$\dot{E}_{\text {Condenser }}(\mathrm{kW})$ & 52.0 & 87.2 & 124.5 & 109.4 \\
$\dot{E}_{\text {Turbine }}(\mathrm{kW})$ & 19.1 & 14.3 & 3.7 & 7.2 \\
$\dot{E}_{\text {Exhaust }}(\mathrm{kW})$ & 49.8 & 17.1 & 17.1 & 17.1 \\
$\dot{E}_{\text {Process }}(\mathrm{kW})$ & 220.2 & 218.5 & 299.3 & 274.7 \\
\hline
\end{tabular}

a) Water quality $\mathrm{x}=0.908$

It is observed from Table 1 that for water the volumetric flow rate at the turbine outlet is much smaller than those for the other fluids. The obvious reason is that water exits the turbine not as a superheated vapour but as a mixture of liquid and vapour (vapour quality $\mathrm{x}=0.908$ ). The flow rate for heptanes is the highest followed by SES36 and R245fa. The flow rates at the turbine inlet are of the same order of magnitude.

In Figure 3 the total efficiency results for heptane are shown as a function of pressure and turbine entrance temperature. It is recognized that the efficiency drops with maximum temperature. This is easily explained by the shape of the T-s Diagram (not shown) which leads to superheated vapour at the turbine exit and thus, to an increased average temperature of heat rejection. This is not balanced by the increased average temperature of heat addition to the cycle. Therefore, for a given pressure the state at the turbine entrance is best chosen as saturated vapour for such a simple Rankine cycle. Regarding the pressure, the highest possible is recommended, in the present case this is restricted to 16 bar (due to safety reasons and the possibility of using single stage turbine). This leads to a maximum total thermal efficiency of $12.2 \%$, while the thermal efficiency of the Rankine cycle is $14.8 \%$. Most of the difference comes from the exhausting of relatively hot air, thus, not all of the $1000 \mathrm{~kW}$ are transferred due to the pinch point. The exergy losses drop with increasing total efficiency, as seen in Table 1, thus only total efficiencies are discussed in the following.

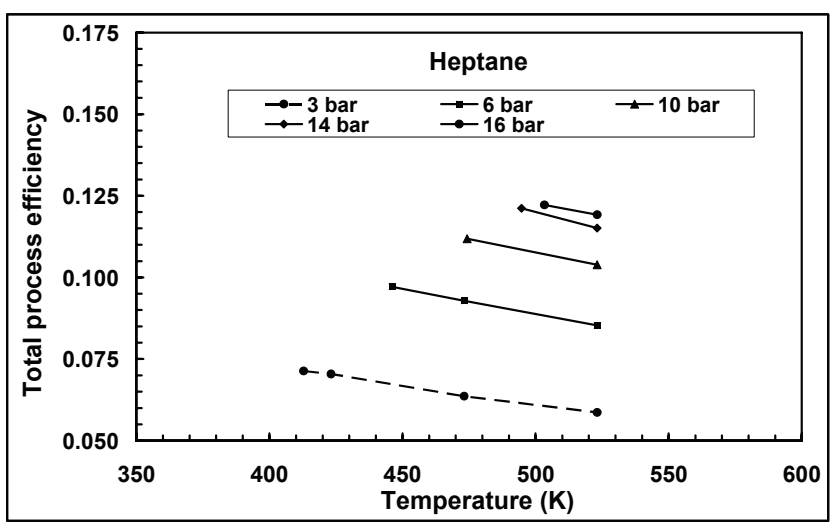

Figure 3. The total thermal efficiency of the process for $n$ heptane as a function of upper pressure level and the turbine entrance temperature $T_{F, 3}$.

The situation is similar for the other two organic fluids, but less favourable. This is shown in Figure 4 where the results for the four fluids are compared for the maximum pressure of 16 bar, which leads throughout to the highest total efficiency. The lowest efficiencies are found for the refrigerant R245fa, while the efficiencies for SES36 is slightly better, but far from those of heptane and water. It is also noticed that with all the three organic liquids the efficiency decreases with increasing temperature level and is highest without superheating. Similar results were reported in (Yamamoto, Furuhata, Arai \& Mori, 2001). Water as working fluid exhibits the highest ORC cycle efficiency as well as the total process efficiency. This increases with the increasing higher (boiler) pressure level and with superheating.

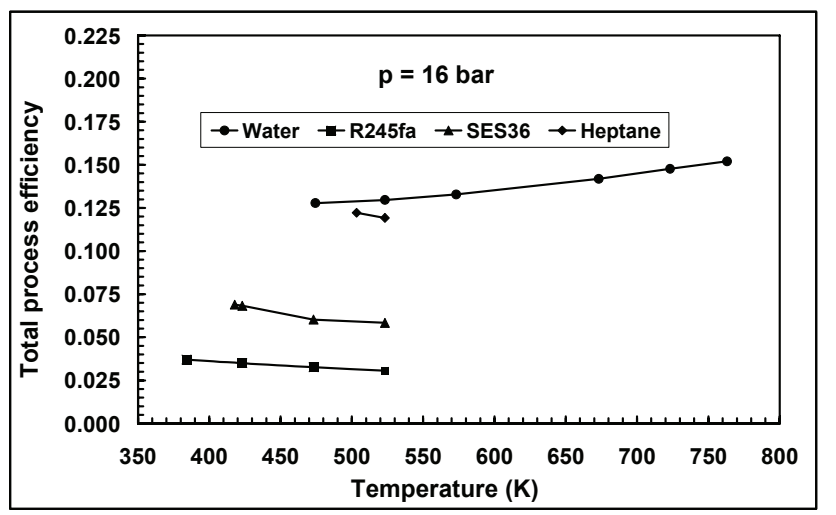

Figure 4. A comparison of the total thermal efficiency of the process for various working fluids at 16 bar.

Examining the total process efficiency at lower pressures (not shown), it is also noticed that the results for heptane approach those for water. This is due to the fact that the hot air stream may leave the heat exchanger at a lower temperature for the organic liquids, because the pinch point for most of the organic liquids is found to be at state 0 , at the outlet of the heat exchanger, whereas for water it is near to state 1 and thus the exhausted air is at a relatively high temperature, leading to a higher 'heat loss'. Depending on the case, $15-25 \%$ of the incoming enthalpy remains unused and is exhausted, this is in part a consequence of the usage of the cycle for cogeneration, leading to relatively high condenser temperatures. This becomes clear if one compares the T-s diagrams of various working fluids. For water the highest total efficiency would be $15.2 \%$, while the thermal efficiency of the cycle is 
$21.5 \%$, the latter being misleading. Regarding the water heating, it is clear from the energy balance, that the remaining energy is split in the part which is used to heat the water to the desired $358 \mathrm{~K}$. Between 60 and $80 \%$ of the initial enthalpy stream are used to heat the cooling water; for heptane at 16 bar; without superheating the value is $71.7 \%$. This means that for an enthalpy stream input of $1000 \mathrm{~kW}, 717 \mathrm{~kW}$ heating power at $85^{\circ} \mathrm{C}$ would be available. This amount of heating power was regarded as sufficient, so the main concern was the electrical power output.

The process and its partial deficiencies are easiest rationalized in $T-\dot{H}$ diagrams (Bejan, Tsatsaronis \& Moran, 1996) where not only the Rankine cycle, but also the process lines for the air and the cooling water are included. The temperature differences along the heat transfer processes can easily be seen as a direct measure of thermodynamic irreversibilities. One example is seen in Figure 5 for heptane with superheating to $523 \mathrm{~K}$. The number 4 marked on the graph indicates the state at the turbine exit.

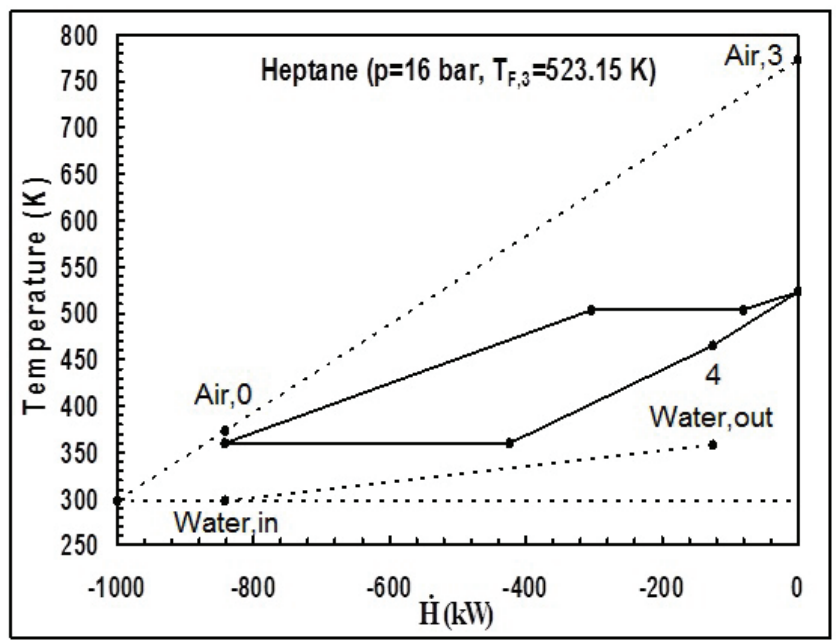

Figure $5 T$ - $\dot{H}$ diagram for n-heptane for superheating to $523.15 \mathrm{~K}$ at $16 \mathrm{bar}$. The condenser pressure is $71.2 \mathrm{kPa}$ $\left(T_{F, s a t}=360 K\right)$.

The exergy losses would be minimized when the lines along the heat transfer from and to the cycle fall on each other. However, the distance between the upper dotted line, which shows the temperature change of the heat source (hot air) from high to low temperature, and the upper part of the full curve showing the change of temperature of the cycle fluid heptane from a sub-cooled liquid to a superheated vapour increases with the temperature difference between the hot and cold streams. It is easily recognized that the mean temperatures of these two fluids differ considerably, leading to large exergy losses in heat transfer. This is also true for the heat transfer in the condenser. The low dotted line shows the temperature increase of the cooling water, while the distance to the full curve is quite large. It is also recognized that the average temperature of heat rejection from the cycle is considerably above the saturation temperature, leading to reduced efficiencies.

The situation is worse for the two other investigated fluids; the $T-\dot{H}$ diagram for R245fa is shown in Figure 6 . The distance between the heat source line and the cycle gets extremely large leading to negligible thermal efficiencies and total efficiencies. It is also seen that the effect of superheating is negative, because the average temperature of heat rejection increases faster than the mean temperature of heat addition to the cycle. The question arises, why is the situation more favourable for water as the cycle fluid? Inspecting the $T-\dot{H}$ diagram for water (Figure 7) it is found that the main advantage, compared to heptane, is not the heat addition to the cycle as the average temperature in this part remains relatively low as long as the pressure remains in the range around 16 bar. But the temperature of heat rejection is much lower, leading to slightly higher total efficiencies. Compared to R245fa, both temperature levels are more favourable.

If we look into the exergy losses given in Table 1 for various steps we find that the exergy losses in boiler and condenser are the main exergy losses, both being smallest for water. For R245fa and SES36 these are 50\% (or more) higher than those for water and heptanes. The exergy losses in the condenser are mainly due to the relatively high average temperatures of heat rejection of the working fluid. This could be in part be improved using an internal heat transfer to the fluid leaving the pump (discussed later in this section). The exergy loss rate in the exhaust is higher for water as a consequence of the higher exhaust temperature which results due to the pinch point restriction. The exergy loss rate for the complete process is small for water and heptanes as compared to refrigerants R245fa and SES36.

Further improvements of the organic Rankine cycles for CHP were investigated. The pressure level in the condenser can also be fixed after performing a pinch point analysis for the condenser. This was not done in the initial calculations, where the saturation pressure at a temperature of $90^{\circ} \mathrm{C}$ was selected. This reduction of the condenser pressure helps to reduce the average temperature of heat rejection and is shown in Figure 8. The total efficiency for this case is increased considerably from $11.9 \%$ to $15 \%$. This efficiency is even superior to water, where similar improvements by changing the condenser conditions are not possible, since the pinch point is already defined at the condenser entrance.

A second well-known approach was also investigated, which is the addition of an internal recuperator to use a part of the enthalpy of the fluid leaving the turbine to preheat the fluid exiting the pump.

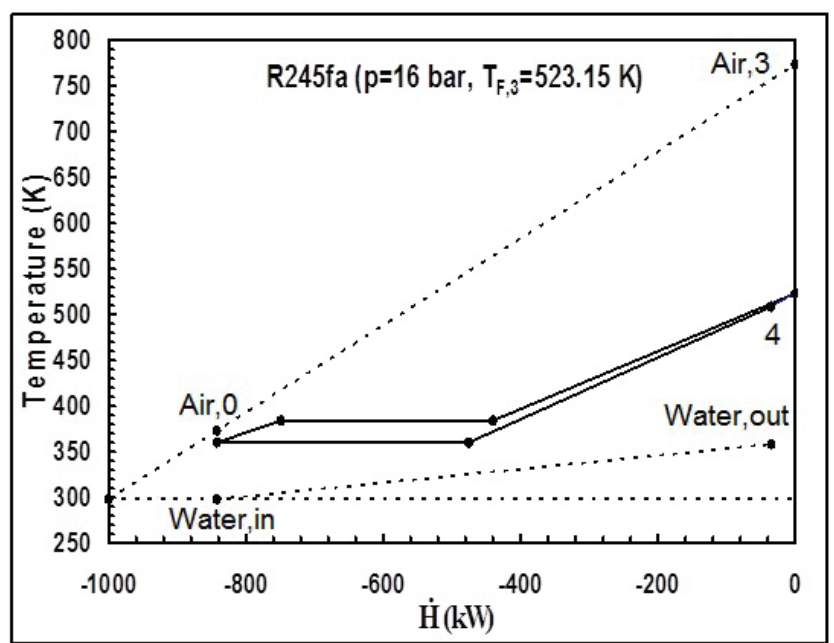

Figure 6. $T$ - $\dot{H}$ diagram R245fa for a superheating at $523.15 \mathrm{~K}$ as a function of upper pressure level. 


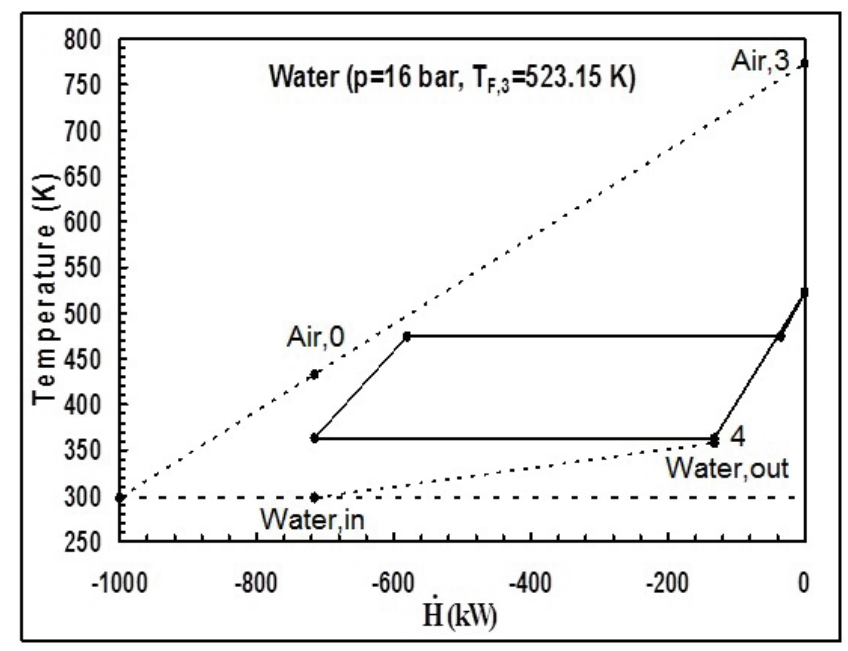

Figure 7. T- $\dot{H}$ diagram water for a superheating at 523.15 $K$ as a function of upper pressure level.

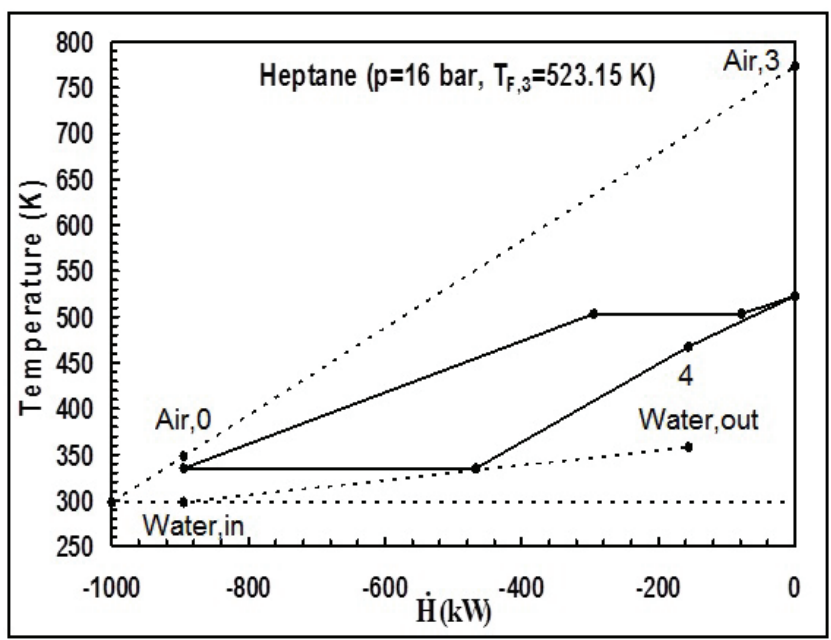

Figure $8 T$ - $\dot{H}$ diagram n-heptane for a superheating at $523.15 \mathrm{~K}$ at a reduced condenser pressure of 0.3007 bar at $p_{\text {boiler }}=16$ bar.

Regarding the cycle and with the parameters given in Table 1, including such a heat exchanger increases the total efficiency for heptane as the cycle fluid to $14.3 \%$, and the thermal efficiency of the cycle would even be increased to $21.4 \%$.

As mentioned earlier, one important cost factor for these cycles is the heat exchanger. The estimated heat exchanger area may be regarded as one important measure of the relative investment costs. The values from Table 1 give some insight: The heat exchanger area for water is throughout smaller by approximately $30 \%$ at 16 bar compared to the organic fluids. In part this difference comes from the different mass flow rates, originating from the different enthalpy levels. At lower evaporator pressures the difference is smaller, but these cases are less interesting. Including an internal heat exchanger increases the size by a further $15-20 \%$, while the reduction of the condenser pressure to the lowest possible value leads to an increase of $10 \%$.

In total the question arises whether the quite small increase in thermal efficiency is worth choosing an organic fluid as the working fluid. The advantages of water as a cheap, harmless, non-ignitable and well-established fluid may outweigh the small difference in total thermal efficiency. Also the total size of the process would be considerably smaller, as seen from the mass flow rates and heat exchanger areas.

If the needed amount of heating power is lower, another approach is worth consideration: The condenser pressure could be reduced to a reasonable minimum and the exhaust gas temperature $\mathrm{T}_{\text {air }, 0}$ could be increased. The exhausted air at a higher temperature could be used for heating, while the cooling water would no longer be useful for this purpose. However, the reduction of the condenser temperature may compensate for this. To investigate this possibility, a series of calculations for an evaporator pressure of 16 bar, were performed. The condenser pressure was chosen at the saturation pressure of the given fluid at $323 \mathrm{~K}$ and the exhaust gas temperature $\mathrm{T}_{\text {air, } 0}$ was increased and fixed to $175^{\circ} \mathrm{C}(448.15 \mathrm{~K})$. The latter temperature leads to a maximum heating power of $316 \mathrm{~kW}$, compared to $600-800$ $\mathrm{kW}$ in the initial approach. However, the total thermal efficiency for water as a working fluid is increased to values between $16.7 \%$ and $18.7 \%$, depending on the exact temperature. This approach is less effective for heptane, for which the total efficiencies change to a value of $13 \%$.

In summary several combined heat and power generation processes to use exhaust gases from engines seem promising.

\section{Conclusions}

Rankine cycles working with four different fluids were investigated for their usage in combined heat and power generation systems which utilize the waste enthalpy stream of typical combustion engines. For this investigation a fixed temperature level of $500^{\circ} \mathrm{C}$ was assumed. It turns out that the total efficiency of energy conversion has to be regarded and not only the efficiency of a given cycle, mainly because the largest exergy losses come from the heat transfer through relatively large temperature differences to and from the cycle. Also the energy source is not isothermal along the heat transfer. If this is neglected, the fluid for the best cycle but not for the highest total energy conversion efficiency will be chosen.

It seems that there is not a single simple criterion for the selection of the best fluid. However the usage of $T-\dot{H}$ diagrams (Bejan, Tsatsaronis \& Moran, 1996) is perhaps the best and most intuitive way to judge the performance or the weakness of a certain combination of a fluid and the heat source and heat sink, as was also done in (Drescher \& Brüggemann, 2007; Saleh, Koglbauer, Wendland \& Fischer, 2007) but is not often found in the recent publications about fluid selection for ORC's. As it was shown for the presented selection of fluids, water may be a good choice for these conditions, even if the steam generator pressure is not selected too high, so that a single turbine stage is sufficient and also the process safety is easier to be ensured. Under certain conditions the alkane heptane leads to a higher total efficiency with the drawback of larger heat exchanger areas and being more expensive than water and flammable. The two fluorinated hydrocarbons are not suited for the investigated temperature range, where e.g. the exhaust of Diesel generators may be used.

Other hydrocarbons or siloxanes may be even a better choice than water or heptane. They will be investigated in near future. 


\section{Acknowledgements:}

Some of the calculations were done by Florian Müller. This is gratefully acknowledged.

\section{Nomenclature:}

A area (surface area for heat exchanger, $\mathrm{m}^{2}$

$c_{p \text {,air }} \quad$ specific heat capacity of air, $\mathrm{kJ} /(\mathrm{kg} \mathrm{K})$

$\dot{E}_{\text {Boiler }} \quad$ exergy loss rate in boiler

$\dot{E}_{\text {Condenser }}$ exergy loss rate in condenser

$\dot{E}_{\text {Exhaust }} \quad$ exergy loss rate in exhaust

$\dot{E}_{\text {Process }} \quad$ exergy loss rate in the complete process

$\dot{E}_{\text {Turbine }} \quad$ exergy loss rate in turbine

$\dot{H}$

$h_{\text {air }, i}$

$h_{F, i}$

$k_{i, j}$

$\dot{m}_{\text {air }}$

$\dot{m}_{F}$

ORC

$P_{\text {net }}$

$P_{\text {pump }}$

$P_{\text {turbine }}$

$p_{\text {boiler }}$

$p_{\text {cond }}$

$\dot{Q}_{a d d, i j}$

$q_{i j}$

sat

surr

$T$

$T_{\text {air }, i}$

$T_{F, i}$

$T_{F, \text { sat }}$

$T_{W, i}$

$\dot{V}_{i}$

$v$

$w_{P}$

$w_{5,0}$

$w_{P, W}$

$\eta_{P}$

$\eta_{P, W}$

$\eta_{\text {th, ORC }}$

$\eta_{\text {th,total }}$

$\Delta T_{L M T D, i j}$ logarithmic mean temperature difference between state $i$ and $j, \mathrm{~K}$

$\Delta T_{i} \quad$ difference between the temperature of air and that of fluid in state $i, \mathrm{~K}$

$\Delta T_{\text {pinch }}$ difference between the temperature of hot air and the fluid at pinch point

\section{References:}

Angelino, G., Colonna di Paliano, P. (2000a). Organic Rankine cycles (ORCs) for energy recovery from molten carbonate fuel cells. $35^{\text {th }}$ Intersociety Energy Conversion Engineering Conference Los Vegas, Nevada, U.S.A.

Angelino, G., Colonna di Paliano, P. (2000b). Air cooled siloxane bottoming cycle for molten carbonate fuel cells. 2000 Fuel Cell Seminar, No. 114, Portland, Oregon, U.S.A.

Bejan A., Tsatsaronis G., J.Moran M. (1996). Thermal design and optimization. New York: Wiley.

Drescher U., Brüggemann D. (2007). Fluid selection for the Organic Rankine Cycle (ORC) in biomass power and heat plants. Applied Thermal Engineering, 27, 223-28.

Hung T. C. (2001). Waste heat recovery of organic Rankine cycle using dry fluids. Energy Conversion and Management, 42, 539-53.

Hung T. C., Shai T. Y., Wang S. K. (1997). A review of organic Rankine cycles (ORCs) for the recovery of lowgrade waste heat. Energy, 22(7), 661-67.

Lai, N. A., Wendland M., Fischer J. (2011), Working fluids for high-temperature organic Rankine cycles. Energy, 36, 199-211.

Lemmon E. W., Huber M. L., Mclinden M. O. (2007). NIST Standard Reference Database 23: Reference Fluid Thermodynamic and Transport Properties-REFPROP, Version 8.0, National Institute of Standards and Technology, Standard Reference Data Program. Gaithersburg, 2007.

Mago P. J., Chamra L. M. (2008). Exergy analysis of a combined engine-organic Rankine cycle configuration. Proceedings of the Institution of Mechanical Engineers Part a-Journal of Power and Energy, 222 Part A, 761-70.

Saleh B., Koglbauer G., Wendland M., Fischer J. (2007). Working fluids for low-temperature organic Rankine cycles. Energy, 32, 1210-21.

Solvay GmbH, Solkane Software Version 6.0.1.6. Retrieved Mai 11, 2009, from www.solvayfluor.com/docroot/fluor/static_files/attachments/downloa d.htm.

Yamamoto T., Furuhata T., Arai N., Mori K. (2001). Design and testing of the Organic Rankine Cycle. Energy, 26, 239-51. 